Ophthalmologica 1966;151(Suppl. 1):I-VII

\title{
Contents, Vol. 151, Supplement 1, 1966
}

Inhaltsverzeichnis

A. Einkitung

Pilze als Krankheitserreger in der Augenheilkunde

1

Histoplasmose 3

Coccidioidomykose $\quad 9$

Cryptococcose 10

Nordamerikanische Blastomykose

Sporotrichose

12

Mucormykose

Aspergillose

12

Aktinomykose und Nocardiose

Candidamykose 15

B. Begründung und Erläuterung des experimentellen Vorhabens

C. In experimenteller Hinsicht bedeutsame anatomische Unterschiede zpischen KaninchenundMenschenauge

D. Methodik

Vorbemerkung. Stellung der Candida albicans (C. a.) im botanischen System sowie ihre morphologischen und biologischen Eigenschaften 23

Züchtung der Erreger 25

Wägung der Kulturmengen, Wahl der Suspendierungsflüssigkeit und Zäh-lung der Blastosporen 26

Technik der Tierversuche

27

E. Versuchsergebnisse

a) Ophthalmoskopisches Bild der Entzündung

Qualitative Untersuchungen 28

Quantitative Untersuchungen 35

Histologisches Bild der Entzündung

Mikrobiologische Untersuchungen

Rückzüchtungen aus dem Auge

Tierpassagen

59

Immunitätsversuche

61

F. Besprechung der Ergebnisse

63

G. . Zusammenfassung

H. L·iteratur

78 